\title{
Palliative care needs in hospitalized cancer patients: a 5-year follow-up study
}

\author{
A. Sandgren ${ }^{1}\left(\mathbb{D} \cdot\right.$ P. Strang $^{2}$
}

Received: 28 March 2017 / Accepted: 10 July 2017 / Published online: 19 July 2017

(C) The Author(s) 2017. This article is an open access publication

\begin{abstract}
Purpose The aims of this study were to describe and compare diagnoses, symptoms, and care needs in palliative cancer patients in two medium-sized hospitals in a county council with no specialized palliative care available $24 / 7$; to analyze the relationships between diagnosis and symptoms/care needs; and to compare results and trends from two datasets (from 2007 and 2012).

Methods The study was population-based with a crosssectional design and was conducted at two acute care hospitals. We performed 142 one-day inventories $(n=2972)$ in 2007 and 139 in $2012(n=2843)$ to register symptoms, care needs, and diagnosis based on a questionnaire. Multiple logistic regression models were used in the analysis.

Results During 2007 and 2012 combined, 10\% ( $n=589)$ of hospitalized patients were assessed as having cancer in a palliative phase. Prostate $(12 \%)$ and colorectal $(12 \%)$ cancers were most common. Pain (42\%) and deterioration (42\%) were the most prevalent symptoms and were associated with pancreas cancer in our regression models $(p=0.003$ and $p=0.019$, respectively). Other cancers had different associations: hematologic malignancies were associated with infections and blood transfusions $(p<0.001)$, breast cancer with pleurocentesis $(p=0.002)$, and stomach/esophagus cancer with nausea $(p<0.001)$. Nausea was more common in women than in men $(p<0.01)$. The mean number of symptoms/care
\end{abstract}

A. Sandgren

anna.sandgren@lnu.se

1 Center for Collaborative Palliative Care, Department of Health and Caring Sciences, Linneaus University, SE-351 95 Växjö, Sweden

2 Department of Oncology-Pathology, Karolinska Institutet, Stockholm and Stockholms Sjukhems FoUU, Stockholm, Sweden needs was 2.9; patients with stomach/esophagus cancer had the highest number of symptoms/care needs (3.5).

Conclusions Acute care hospitals still play an important role for patients requiring palliative care. Symptoms and care needs were not strongly associated with specific diagnoses. Therefore, symptoms, rather than the specific cancer diagnoses, should be the focus of care.

Keywords Cancer $\cdot$ Hospitalization $\cdot$ Palliative care $\cdot$ Population-based $\cdot$ Symptom $\cdot$ Care needs

\section{Introduction}

Due to improved treatment options, patients live longer in the palliative phase of cancer [1-3]. For example, the mean survival for metastatic colorectal cancer was about 7-10 months in 1990s; this increased to about 20 months in 2010 [4]. The longer survival and preserved or even improved quality of life is not only related to improved cancer treatments, but is also associated with better supportive care and with the introduction of palliative interventions earlier in the course of advanced cancer [5]. A recent review showed benefit in integrating palliative interventions with cancer-specific treatments [5], as standard treatment plus palliative care interventions improve quality of life and result in prolonged survival, at least in patients with lung cancer [6].

Worldwide, palliative care has developed and evolved in recent years, although in some countries, the majority of the population lacks access to palliative care [7]. Even though specialized palliative care has long formed part of healthcare in Sweden, such care is not equally distributed [8]. Certain county councils (e.g., those of Stockholm and Östergötland) have developed specialized palliative care units: Some operate 24/7 and include palliative care teams and palliative units/ 
hospices and others have specialized palliative counseling teams available only during the daytime, from Monday to Friday [9]. This means that acute care hospitals remain the only option for certain patients with acute palliative care needs. However, hospitals are not ideal settings for palliative care patients, as lack of staff and increased time pressure are common problems [10], and the emotional strain of caring for palliative patients can be a challenge [11]. Moreover, healthcare professionals first need to recognize patients as being "palliative" and then need to have a readiness to discuss optimal, not maximal, care during their hospitalization [12].

Studies have mainly focused on the extent of symptoms and palliative care needs of cancer patients in hospices and palliative care units/programs [13-16], but some have focused on cancer patients in hospital settings [17-20]. Nonetheless, we still need more knowledge regarding the extent of palliative care needs and the prevalence and characteristics of symptoms in acute care settings in regions with limited availability of specialized palliative care. Thus, the aim of this study was to describe and compare diagnoses, symptoms, and care needs in palliative cancer patients in two medium-sized hospitals in a county council with no specialized palliative care available 24/7. Further aims were to analyze the relationships between diagnosis and symptoms/care needs and to compare results and trends from two sets of data (one from 2007 and the other from 2012).

\section{Methods}

\section{Design and setting}

This cross-sectional, population-based study was carried out during 2007 and 2012 in the departments of Oncology, Surgery, and Internal medicine in two hospitals, serving almost 187,000 individuals, in a medium-sized county in southern Sweden. The county had no palliative care units and 24-h specialist palliative care services were not available during the study period. During daytime hours, Monday to Friday, a palliative advisory team served the population. However, the palliative advisory team was affiliated with the hospitals, facilitated contacts between the hospitals and the home healthcare providers, and supported the healthcare professionals. The team increased its staff from six nurses and one physician working halftime in 2007 to six nurses, three physicians working halftime, and one social worker in 2012.

\section{Questionnaire}

A questionnaire with 14 items was used. It was developed by representatives of different professions and had been pilottested and used in earlier studies [19]. In short, the questionnaire comprises organizational and healthcare aspects (clinic wards, number of beds, etc.), demographic data (age, sex, etc.), and symptoms as well as care needs. A total of 23 different symptoms and/ or interventions (e.g., "pleurocentesis") were listed and the staff registered all the needs of the respective patient. In order not to miss relevant interventions, the staff was also invited to write free comments. The WHO's definition of palliative care was also included [21] as an aid for the assessments. The questionnaire was pilot-tested in 2002 for face and content validity by a panel of palliative care experts [19].

\section{Data collection}

We met with the nurses in charge of the different wards in 2007 and 2012 to discuss how to assess a patient as being in a palliative phase and how to complete the questionnaire. To get comparable assessments, it was of utmost importance that each nurse knew how to assess a patient as being in a palliative phase, i.e., when their cancer was no longer responsive to curative treatment and carried a limited prognosis.

Data were collected in 12 wards: one oncology ward (17 beds), four surgical wards ( 89 beds in 2007; 85 beds in 2012), and seven medical wards (153 beds in 2007; 162 beds in 2012). Using the questionnaire, nurses and physicians, in cooperation, made the registrations on a specified day every month. In 2007, there were 142 registrations (data were missing for two days, i.e., 1.4\%), and in 2012, there were 139 registrations (data missing for five days, i.e., $3.5 \%$ ). In total, 2972 patients were assessed in 2007 and 2843 in 2012.

\section{Statistical analysis}

IBM SPSS statistics, version 21 (IBM Corp, Armonk, NY, USA), was used to perform univariate and multivariate analyses, Pearson's chi-square test, Wilcoxon's test, and multiple logistic regression. First, we analyzed the data from the respective years, but due to few differences between the years, we decided to combine the two datasets. In the results, we present the differences found between the years.

To analyze associations between diagnosis and each symptom/care need, we performed multiple logistic regression analyses (using a backward stepwise method and the likelihood ratio test). Before performing these analyses, we assessed bivariate associations between each symptom/care need and diagnosis and only included the symptoms/care needs that were associated the diagnosis with a $p$ value $\leq 0.20$. Nagelkerke $R$-square statistics were calculated to evaluate the strength of the association between the diagnosis and symptoms/care needs. All analyses were controlled for sex and age. $p$ values $<0.05$ were regarded as statistically significant. 


\section{Ethical considerations}

The study was conducted in accordance with the Declaration of Helsinki of the World Medical Association [22]. Since the study did not involve any identifiable patient data, Swedish law and praxis consider this study as a part of normal clinical improvement procedures and approval by the Regional Ethics Committee was thus not necessary. Instead, ethical approval for the study was received from the operation managers and the heads of the departments at the hospitals. Written information about the study was then sent out to the head nurses of the participating wards who selected a responsible nurse for the study.

\section{Results}

During 2007 and 2012 combined, 10\% of all hospitalized patients were assessed as being palliative cancer patients $(n=589)$. Of these, $53.7 \%$ were men and $46.3 \%$ women. The patients' average age was 73 years (range 29-98 years), with no significant difference between the sexes. The oncology and surgical wards had the highest rates of palliative patients admitted (40.1 and 39.2\%, respectively), while medical wards had the lowest $(20.7 \%)$. There were more women in the oncology and surgical wards and more men in the medical wards, although the difference was non-significant.

\section{Diagnoses}

Prostate, colorectal, and lung cancer were the most frequent diagnoses (Table 1). Urologic cancer was significantly more prevalent in men, even when excluding sex-related diagnoses $(p<0.01)$. Patients with gynecologic cancers were the youngest (mean age 67 years) while patients with prostate cancer were the oldest (mean age 78 years).

\section{Symptoms/care needs}

Pain and deterioration were the most prevalent symptoms, even when studying men and women separately. Deterioration in this article refers to progressively increasing weakness. Nausea was among the top four symptoms for women, but

Table 1 Top five diagnoses of palliative cancer patients

\begin{tabular}{lll}
\hline All, \% $(n=589)$ & Men, \% $(n=316)$ & Women, \% (n=273) \\
\hline Prostate (12.4) & Prostate (23.1) & Gynecologic (15.4) \\
Colorectal (12.1) & Lung (12.7) & Breast (14.3) \\
Lung (11.7) & Hematologic (12) & Colorectal (12.8) \\
Hematologic (10.5) & Colorectal (11.4) & Lung (10.6) \\
Pancreas (8.0) & Urologic (9.2) & Pancreas (8.8) \\
& & Hematologic (8.8) \\
\hline
\end{tabular}

was not in the top five symptoms for men $(p<0.01)$. The distribution of symptoms and care needs are listed in Table 2.

The mean number of symptoms/care needs as a main reason for hospitalization for each patient was 2.9, with no significant difference between men and women. Patients with prostate cancer (2.5) and patients with lung and urologic cancers (2.6) had the lowest numbers of symptoms/care needs, while patients with stomach/esophagus and pancreas cancers had the highest (3.5 and 3.4, respectively).

\section{Relationships between diagnosis and symptoms/care needs}

The most prevalent symptoms for all patients were pain and deterioration, as previously mentioned. In our regression models, pain $(p=0.003)$ and deterioration $(p=0.019)$ were associated only with pancreas cancer in our final model (Table 3). Patients with colorectal cancer had a higher occurrence of abdominal surgery than other patients $(p<0.001)$, while admission of those with hematologic malignancies was associated with infections and blood transfusions $(p<0.001)$, breast cancer with pleurocentesis $(p=0.002)$, and stomach/ esophagus cancers with nausea $(p<0.001)$, as shown in Table 3. Even though none of our final models were exhaustive, several models had a Nagelkerke $R$-square $>0.3$.

\section{Differences between the years 2007 and 2012}

We found no significant difference between the years regarding the sex or age of the patients. When comparing diagnoses over the years, the proportion of patients with hematologic malignancies had decreased (12 vs 3\%) ( $p<0.001)$. As regards reasons for hospitalization, the need for nutrition (3 vs $21 \%$, $p<0.001)$ and pleurocentesis (2 vs 7\%,p<0.01) had increased, whereas social issues (17 vs $8 \%, p<0.01)$ had decreased.

\section{Discussion}

Approximately $10 \%$ of the assessed patients in acute hospital wards were cancer patients with distinct palliative care needs. This figure is comparable with those of other studies, even though there are differences between studies due to methodological differences [12, 17, 20, 23]. In a study in a New Zealand Hospital, 9.2\% of cancer patients were assessed to have a palliative care need [23], whereas the corresponding figure in general hospitals in Belgium was $4.8 \%$ [12].

The current study was partially done in order to identify trends in symptoms and care needs over the years. However, when comparing the 2007 and 2012 data, most problems were similar. Among symptoms, pain and deterioration dominated (prevalent in more than $40 \%$ of the patients) and were defined as definite reasons for hospital 
Table 2 Prevalence of symptoms/care needs for hospitalized palliative cancer patients

\begin{tabular}{llll}
\hline Symptoms/care needs & $\begin{array}{l}\text { All, }(n=589) \\
(n=316)\end{array}$ & $\begin{array}{l}\text { Men, } \\
(n=273)\end{array}$ \\
\hline Abdominal surgery & 5.3 & 4.7 & 5.9 \\
Blood transfusion & 12.6 & 13.6 & 11.4 \\
Deterioration & 42.3 & 39.6 & 45.4 \\
Diagnostic procedure & 22.6 & 22.5 & 22.5 \\
Fatigue (only 2012) & 13.4 & 13.0 & 13.9 \\
Infection & 24.3 & 26.9 & 21.2 \\
Infusion & 11 & 9.5 & 12.8 \\
Nausea & $17.7 *$ & 13.6 & 22.3 \\
Nutrition & 11 & 11.1 & 11.0 \\
Obstipation & 8 & 7.3 & 8.8 \\
Pain & 42.3 & 42.7 & 41.8 \\
Paracentesis & 3.9 & 3.2 & 4.8 \\
Pleurocentesis & 4.1 & 3.2 & 5.1 \\
Psychosocial issues & 16.8 & 15.5 & 18.3 \\
Radiotherapy & 17.1 & 19.8 & 14.7 \\
Social issues & 12.9 & 12.7 & 13.2 \\
Surgical procedure/stenting & 10 & 10.8 & 9.2 \\
Other & 15.3 & 14.2 & 16.5 \\
\hline
\end{tabular}

*Significant difference between men and women

care. The prevalence of pain and deterioration did not significantly increase or decrease between 2007 and 2012. This finding raises some questions. Pain is common in cancer patients with advanced disease [24] but in most cases, it should be possible to manage this in the primary care or home care setting. Also, early access to an integrated palliative care team can reduce the occurrence of symptoms, including pain. Bandieri et al. [25] found that early access to an integrated palliative care team was associated with a $31 \%$ reduced risk of suffering from severe pain. However, Holtan et al. [26] found that inadequate pain management, for example the underuse of analgesics, was often caused by a lack of basic knowledge and failure to perform individual pain assessment. Deterioration was the other common reason for hospitalization. This could also easily be managed in the palliative home care setting, provided that the home care team works around the clock with access to registered nurses, physicians, and paramedics. Although most symptoms and care needs remained constant between the years, there were some exceptions, such as a clear decrease in the proportion of patients with nausea (from 13 to 8\%); this may be related to more effective antiemetic strategies and the introduction of targeted cancer drugs that are less prone to cause nausea. Several of the symptoms and care needs were of a nature that is regularly treated in the specialized palliative home care setting. Moreover, many of the interventions stated as reasons for hospital care are possible to manage at home, e.g., infusions, blood transfusions, paracentesis, and even pleurocentesis. Although many symptoms can be treated at home, this is not possible for all patients. Abel et al. [27] argue that well-functioning home care could
Table 3 Relationships between diagnosis and symptoms/care needs $(n=589)$

\begin{tabular}{|c|c|c|c|c|c|}
\hline Diagnosis & Symptoms/care needs & $p$ value & OR & $95 \% \mathrm{CI}$ & $\begin{array}{l}\text { Nagelkerke } \\
R \text {-square }\end{array}$ \\
\hline Breast & $\begin{array}{l}\text { Radiotherapy } \\
\text { Pleurocentesis }\end{array}$ & $\begin{array}{l}0.003 \\
0.002\end{array}$ & $\begin{array}{l}3.6 \\
7.8\end{array}$ & $\begin{array}{l}1.5-8.2 \\
2.1-28.7\end{array}$ & 0.371 \\
\hline Colorectal & Abdominal surgery & 0.000 & 8.4 & $3.8-18.6$ & 0.137 \\
\hline \multirow[t]{2}{*}{ Gynecologic } & $\begin{array}{l}\text { Abdominal surgery } \\
\text { Blood transfusion }\end{array}$ & $\begin{array}{l}0.015 \\
0.007\end{array}$ & $\begin{array}{l}4.9 \\
3.8\end{array}$ & $\begin{array}{l}1.4-17.9 \\
1.4-10.3\end{array}$ & \multirow[t]{2}{*}{0.416} \\
\hline & Paracentesis & 0.000 & 6.1 & $1.7-22.2$ & \\
\hline Hematologic & $\begin{array}{l}\text { Blood transfusion } \\
\text { Infection }\end{array}$ & $\begin{array}{l}0.000 \\
0.000\end{array}$ & $\begin{array}{l}9.0 \\
5.9\end{array}$ & $\begin{array}{l}4.8-17.9 \\
3.1-11.3\end{array}$ & 0.388 \\
\hline Lung & Obstipation & 0.006 & 3.0 & $1.4-6.7$ & 0.149 \\
\hline \multirow[t]{3}{*}{ Pancreas } & $\begin{array}{l}\text { Deterioration } \\
\text { Pain }\end{array}$ & $\begin{array}{l}0.019 \\
0.003\end{array}$ & $\begin{array}{l}2.2 \\
2.8\end{array}$ & $\begin{array}{l}1.3-4.2 \\
1.4-5.5\end{array}$ & \multirow[t]{4}{*}{0.192} \\
\hline & Paracentesis & 0.000 & 6.6 & $2.3-18.8$ & \\
\hline & $\begin{array}{l}\text { Surgical } \\
\quad \text { procedure/stenting }\end{array}$ & 0.000 & 7.1 & $3.3-15.4$ & \\
\hline Prostate & None & & & & \\
\hline Stomach/esophagus & $\begin{array}{l}\text { Nausea } \\
\text { Surgical } \\
\quad \text { procedure/stenting }\end{array}$ & $\begin{array}{l}0.000 \\
0.001\end{array}$ & $\begin{array}{l}4.1 \\
3.8\end{array}$ & $\begin{array}{l}1.9-8.7 \\
1.7-8.4\end{array}$ & 0.227 \\
\hline Unknown primary & $\begin{array}{l}\text { Abdominal surgery } \\
\text { Diagnostic procedure }\end{array}$ & $\begin{array}{l}0.011 \\
0.005\end{array}$ & $\begin{array}{l}4.7 \\
2.3\end{array}$ & $\begin{array}{l}1.4-15.8 \\
1.4-7.4\end{array}$ & 0.113 \\
\hline Urologic & None & & & & \\
\hline
\end{tabular}

$O R$ odds ratio, $C I$ confidence interval 
have been a viable option for up to a third of patients who died in their specific hospital setting.

The number of symptoms/care needs was the highest for patients with stomach/esophagus cancer (3.5) and the lowest for patients with prostate cancer (2.5). This finding has implications: patients with disseminated cancer seldom have single symptoms but rather a cluster of symptoms [16, 28]. Therefore, comprehensive care focused on several physical and psychosocial issues is recommended. For example, optimal treatment of pain does not solve the problem for a patient in the acute hospital setting unless there is also a care plan and a suitable service to address problems associated with deterioration and psychosocial issues. The statistical relationship between certain diagnoses and symptoms/care needs is interesting. As expected, the odds ratio for pleurocentesis was high for those with metastatic breast cancer and paracentesis was associated with gynecologic and pancreatic cancers, whereas blood transfusions and infections were common in patients with hematologic malignancies. Knowledge of the prevalence of symptoms and care needs is important when formulating management plans; it contributes to the rational planning of cancer and palliative care services [29]. However, even though certain symptoms were statistically associated with specific diagnoses, it is important to emphasize that symptoms were common in most diagnoses. Indeed, although both pain and deterioration were common symptoms and reasons for hospitalization, they were not strongly associated with specific cancer diagnoses. This is in line with an old observation that symptoms that may be specific for a certain cancer diagnosis in earlier stages become more generic in end-of-life care [30]. Therefore, skills in treating certain symptoms are probably more important than specific knowledge of a certain cancer diagnosis, as regards the palliative care of cancer patients.

Bruera and Hui [31] highlight that oncologists need to have the core competencies of palliative care in order to ensure a high quality of care for the patients. Healthcare professionals need to recognize patients as requiring palliative care in order to meet their common and specific needs [12]. However, many generalists struggle to identify such patients [32]; this is true both for patients in early and more advanced palliative stages. To optimize the care and quality of life of patients with palliative care needs, such care should be integrated early in the disease trajectory, in line with the WHO's definition, and should be seen as an important component of care [33-35]. To accomplish this, healthcare professionals need education and support to provide palliative care in order to facilitate the living dignity of cancer patients, despite their diagnosis or life expectancy [12].

\section{Limitations of the study}

There are some limitations to this study. First, symptoms and care needs were assessed by healthcare professionals and not by the patients themselves. However, our aim was not to cover all symptoms or their severity but rather to focus on the symptoms and care needs that led to hospitalization, according to the staff. Second, even though we had defined "palliative" and had held meetings with persons in charge of each ward, the definition of "palliative" could have been problematic. Earlier studies have highlighted this issue since "palliative" is used in different ways [32, 36].

\section{Conclusions and implications}

The results of our study provide detailed information about symptoms, care needs, and diagnoses in palliative cancer patients admitted to acute care hospitals. We show that hospitals play an important role in palliative care, with $>10 \%$ of hospitalized patients assessed as being "palliative" in this 5-year follow-up study. The fact that symptoms and care needs were not strongly associated with certain diagnoses implies that care should focus on symptoms rather than the specific diagnosis. Healthcare professionals need adequate resources and knowledge about symptom management and palliative care in order to provide good care to these cancer patients during their hospital stay. Early integration of palliative care may also optimize the quality of care. Therefore, it is of highest importance to further investigate how such integration can optimize the quality of care of patients in areas with no specialized palliative care available $24 / 7$.

Acknowledgements We would like to thank Dr. Hans Thulesius for his contribution to the study during 2007. We also would like to thank Per Nyberg for his valuable advice on the statistical analysis. We would like to thank Editage (www.editage.com) for English language editing.

Compliance with ethical standards The study was conducted in accordance with the Declaration of Helsinki of the World Medical Association [22]. Since the study did not involve any identifiable patient data, Swedish law and praxis consider this study as a part of normal clinical improvement procedures and approval by the Regional Ethics Committee was thus not necessary. Instead, ethical approval for the study was received from the operation managers and the heads of the departments at the hospitals. Written information about the study was then sent out to the head nurses of the participating wards who selected a responsible nurse for the study.

Conflict of interest The authors declare that they have no conflicts of interest.

Open Access This article is distributed under the terms of the Creative Commons Attribution-NonCommercial 4.0 International License (http:// creativecommons.org/licenses/by-nc/4.0/), which permits any noncommercial use, distribution, and reproduction in any medium, provided you give appropriate credit to the original author(s) and the source, provide a link to the Creative Commons license, and indicate if changes were made. 


\section{References}

1. Gerber DE (2008) Targeted therapies: a new generation of cancer treatments. Am Fam Physician 77(3):311-319

2. Martins da Rosa L, Radünz V (2012) Survival rates to woman with breast cancer: review. Texto Contexto Enferm 21(4):980-989

3. Brawley OW (2012) Prostate cancer epidemiology in the United States. World J Urol 30(2):195-200. doi:10.1007/s00345-0120824-2

4. Tveit KM, Guren T, Glimelius B, Pfeiffer P, Sorbye H, Pyrhonen S, Sigurdsson F, Kure E, Ikdahl T, Skovlund E, Fokstuen T, Hansen F, Hofsli E, Birkemeyer E, Johnsson A, Starkhammar H, Yilmaz MK, Keldsen N, Erdal AB, Dajani O, Dahl O, Christoffersen T (2012) Phase III trial of cetuximab with continuous or intermittent fluorouracil, leucovorin, and oxaliplatin (Nordic FLOX) versus FLOX alone in first-line treatment of metastatic colorectal cancer: the NORDIC-VII study. J Clin Oncol 30(15):1755-1762. doi:10. 1200/JCO.2011.38.0915

5. Zhi WI, Smith TJ (2015) Early integration of palliative care into oncology: evidence, challenges and barriers. Ann Palliat Med 4(3): 122-131. doi:10.3978/j.issn.2224-5820.2015.07.03

6. Temel JS, Greer JA, Muzikansky A, Gallagher ER, Admane S, Jackson VA, Dahlin CM, Blinderman CD, Jacobsen J, Pirl WF, Billings JA, Lynch TJ (2010) Early palliative care for patients with metastatic non-small-cell lung cancer. N Engl J Med 363(8):733742. doi:10.1056/NEJMoa1000678

7. Lynch T, Connor S, Clark D (2013) Mapping levels of palliative care development: a global update. J Pain Symptom Manag 45(6): 1094-1106. doi:10.1016/j.jpainsymman.2012.05.011

8. Socialstyrelsen (2006) Vård i livets slutskede. Socialstyrelsens bedömning av utvecklingen i landsting och kommuner [End of life care] http://www.socialstyrelsen.se/publikationer2006/2006-103-8

9. Palliativguiden - Swedish directory of specialized palliative care. The Swedish Council for Palliative Care. http://www.nrpv.se/ palliativguiden/. Accessed 1 Sept 2016

10. Gardiner C, Cobb M, Gott M, Ingleton C (2011) Barriers to providing palliative care for older people in acute hospitals. Age Ageing 40(2):233-238. doi:10.1093/ageing/afq172

11. Sandgren A, Thulesius H, Fridlund B, Petersson K (2006) Striving for emotional survival in palliative cancer nursing. Qual Health Res 16(1):79-96

12. Desmedt MS, de la Kethulle YL, Deveugele MI, Keirse EA, Paulus DJ, Menten JJ, Simoens SR, Vanden Berghe PJ, Beguin CM (2011) Palliative inpatients in general hospitals: a one day observational study in Belgium. BMC Palliat Care 10:2

13. Tai SY, Lee CY, Wu CY, Hsieh HY, Huang JJ, Huang CT, Chien CY (2016) Symptom severity of patients with advanced cancer in palliative care unit: longitudinal assessments of symptoms improvement. BMC Palliat Care 15:32. doi:10.1186/s12904-016-0105-8

14. Kirkova J, Rybicki L, Walsh D, Aktas A (2012) Symptom prevalence in advanced cancer: age, gender, and performance status interactions. Am J Hosp Palliat Care 29(2):139-145. doi:10.1177/ 1049909111410965

15. Hui D, dos Santos R, Chisholm GB, Bruera E (2015) Symptom expression in the last seven days of life among cancer patients admitted to acute palliative care units. J Pain Symptom Manag 50(4):488-494. doi:10.1016/j.jpainsymman.2014.09.003

16. Stapleton SJ, Holden J, Epstein J, Wilkie DJ (2016) Symptom clusters in patients with cancer in the hospice/palliative care setting. Support Care Cancer 24(9):3863-3871. doi:10.1007/s00520-0163210-6

17. Ryan T, Ingleton C, Gardiner C, Parker C, Gott M, Noble B (2013) Symptom burden, palliative care need and predictors of physical and psychological discomfort in two UK hospitals. BMC Palliat Care 12:11. doi:10.1186/1472-684X-12-11
18. Spichiger E, Muller-Frohlich C, Denhaerynck K, Stoll H, Hantikainen V, Dodd M (2011) Symptom prevalence and changes of symptoms over ten days in hospitalized patients with advanced cancer: a descriptive study. Eur J Oncol Nurs 15(2):95-102. doi:10. 1016/j.ejon.2010.06.005

19. Sandgren A, Fridlund B, Nyberg P, Strang P, Petersson K, Thulesius H (2010) Symptoms, care needs and diagnosis in palliative cancer patients in acute care hospitals: a 5-year follow-up survey. Acta Oncol 49(4):460-466. doi:10.3109/02841860903463991

20. Meffert C, Rucker G, Hatami I, Becker G (2016) Identification of hospital patients in need of palliative care - a predictive score. BMC Palliat Care 15:21. doi:10.1186/s12904-016-0094-7

21. WHO (2003) WHO - definition of palliative care. World Health Organization. http:/www.who.int/cancer/palliative/definition/en/

22. WMA (2008) World Medical Association Declaration of Helsinki. World Medical Association. http://www.wma.net/e/policy/b3.htm

23. Gott M, Frey R, Raphael D, O'Callaghan A, Robinson J, Boyd M (2013) Palliative care need and management in the acute hospital setting: a census of one New Zealand hospital. BMC Palliat Care 12:15. doi:10.1186/1472-684X-12-15

24. Kaasa S, Haugen DF (2011) Cancer pain research: time to reset the strategy and the agenda. Palliat Med 25(5):392-393. doi:10.1177/ 0269216311407403

25. Bandieri E, Sichetti D, Romero M, Fanizza C, Belfiglio M, Buonaccorso L, Artioli F, Campione F, Tognoni G, Luppi M (2012) Impact of early access to a palliative/supportive care intervention on pain management in patients with cancer. Ann Oncol 23(8):2016-2020. doi:10.1093/annonc/mds103

26. Holtan A, Aass N, Nordoy T, Haugen DF, Kaasa S, Mohr W, Kongsgaard UE (2007) Prevalence of pain in hospitalised cancer patients in Norway: a national survey. Palliat Med 21(1):7-13. doi: 10.1177/0269216306073127

27. Abel J, Rich A, Griffin T, Purdy S (2009) End-of-life care in hospital: a descriptive study of all inpatient deaths in 1 year. Palliat Med 23(7):616-622. doi:10.1177/0269216309106460

28. Tsai J-S, Wu C-H, Chiu T-Y, Chen C-Y (2010) Significance of symptom clustering in palliative care of advanced cancer patients. J Pain Symptom Manag 39:655-662. doi:10.1016/j.jpainsymman. 2009.09.005

29. Potter J, Hami F, Bryan T (2003) Symptoms in 400 patients referred to palliative care services: prevalence and patterns. Palliat Med 17(4):310-315

30. Beck-Friis B (1993) Hospital-based home care of terminally ill cancer patients: the Motala model. Dissertation, Uppsala University, Uppsala

31. Bruera E, Hui D (2010) Integrating supportive and palliative care in the trajectory of cancer: establishing goals and models of care. J Clin Oncol 28(25):4013-4017. doi:10.1200/JCO.2010.29.5618

32. Gardiner C, Gott M, Ingleton C, Seymour J, Cobb M, Noble B, Bennett M, Ryan T (2013) Extent of palliative care need in the acute hospital setting: a survey of two acute hospitals in the UK. Palliat Med 27(1):76-83. doi:10.1177/0269216312447592

33. Gardiner C, Ingleton C, Gott M, Ryan T (2011) Exploring the transition from curative care to palliative care: a systematic review of the literature. BMJ Support Palliat Care 1(1):56-63. doi:10.1136/ bmjspcare-2010-000001

34. Schofield P, Carey M, Love A (2006) 'Would you like to talk about your future treatment options?' discussing the transition from curative cancer treatment to palliative care. Palliat Med 20(4):397-407

35. Milligan S (2012) Optimising palliative and end of life care in hospital. Nurs Stand 26(41):48-56; quiz 58. doi:10.7748/ns2012. 06.26.41.48.c9157

36. Van Mechelen W, Aertgeerts B, De Ceulaer K, Thoonsen B, Vermandere M, Warmenhoven F, Van Rijswijk E, De Lepeleire J (2013) Defining the palliative care patient: a systematic review. Palliat Med 27(3):197-208. doi:10.1177/0269216311435268 